\title{
IMPACT TESTING OF ORDNANCE GELATINE UNDER MODERATE STRAIN RATE CONDITIONS
}

\author{
Tomáš Doktor*, Petr Zlámal, Jan Šleichrt, Tomáš Fíla, \\ DANIEL KYTÝŘ
}

\author{
Czech Technical University in Prague, Faculty of Transportation Sciences, Konviktská 20, Praha 1, Czech \\ republic \\ * corresponding author: doktor@fd.cvut.cz
}

\begin{abstract}
An experimental study on energy absorption capabilities and strain rate sensitivity of ordnance gelatine was performed. Strain energy density under quasi static compression and moderate strain rate impact tests was compared. In the study two types of material were tested, bulk ordnance gelatine and polymeric open-cell meshwork filled with ordnance gelatine. From the results a significant strain-rate effect was observed in terms of ultimate compressive strength and strain energy density. In comparison of the deformation behaviour under quasi static conditions and drop weight test the difference was very significant, however slight increase in both strength and strain energy density was observed even between different impact energies and velocities during the impact testing. The peak acceleration was significantly reduced in polymer meshwork filled by gelatine in comparison to the bulk gelatine.
\end{abstract}

KEYWORDS: ordnance gelatine, strain energy density, impact testing.

\section{INTRODUCTION}

In the engingeering applications in the field of ballistic and blast protection, passive safety systems in vehicles (automotive, railway vehicles) the impact energy dissipation is among the crucial properties [1]. One of the possible solutions to achieve such capabilities is to utilise cellular solids in conjunction with strain rate sensitive filling [2]. In this study experimental investigation on strain rate sensitivity at moderate strain rates as well as the interaction of the cellular solid and viscous filling is described. As filling material ordnance gelatine was selected due to a flawless preparation procedure and availability. The ordnance (ballistic) gelatine is widely used as tissue simulant for assessment of damage of tissues induced by bullets [3]. However strain rate sensitivity under compressive loading was reported as well 4 .

Deformation response of ballistic gelatine blocks (plain and reinforced with polymeric meshwork) under moderate impact loading is described in this paper in terms of peak acceleration during the impact as well as total kinetic energy dissipation.

\section{MATERIALS AND METHODS}

\subsection{SAMPLE PREPARATION}

For both impact and quasi-static testing two types of material were used, (i) bulk ordnance gelatine and (ii) open-cell polymeric meshwork filled with ordnance gelatine. The gelatine was prepared according to the reports of Jussila [5]. As a base, 260 Bloom beef gelatine (REMI MB, Ltd., Czech republic) was used. The gelatine powder was poured into warmed water (temperature was $45^{\circ} \mathrm{C}$ )
In the second group the gelatine was reinforced with polymeric open-cell meshwork FT-S10FR (Foam Techniques, Ltd, United Kingdom) with tetrakaidecahedral cells, mean cell size $6 \mathrm{~mm}$, mean strut thickness $0.6 \mathrm{~mm}$. The dissolved gelatine after homogeneous mixing was poured into the meshwork.

The samples from both batches (both pure and reinforced) were cured for $24 \mathrm{~h}$ in room temperature and subsequently stored for $24 \mathrm{~h}$ in refrigerator. After this curing the blocks were cut into samples of desired size. In the quasi static loading conditions the size of samples was $25 \times 25 \times 50 \mathrm{~mm}$, and samples' size for impact testing was approximately $60 \times 50 \times 50 \mathrm{~mm}$. Dimensions of the samples were limited by diameter of used loading plates. To ensure a better focus during optical observation captured face of each sample was sprayed granit paint to obtain random pattern.

\subsection{QuAsi STATIC TESTS}

The quasi static tests were performed using electromechanic uniaxial loading device Instron 6530 (Instron, Inc., USA). The compressive tests were displacement driven with loading rate $3 \mathrm{~mm} \cdot \mathrm{min}^{-1}$, which corresponded to strain rate $0.001 \mathrm{~s}^{-1}$. Maximum displacement was set to $30 \mathrm{~mm}$.

\subsection{IMPACT TESTS INSTRUMENTATION}

The moderate strain rate compression tests were performed by an in-house drop tower developed at CTU FTS [6]. The drop weight is released by electromagnetic member and then guided on steel rods and induces the impact on a sample places at a stable plate. The drop-tower setup was instrumented by triaxial accelerometer (EGCS3, TE Connectivity, Ltd., 


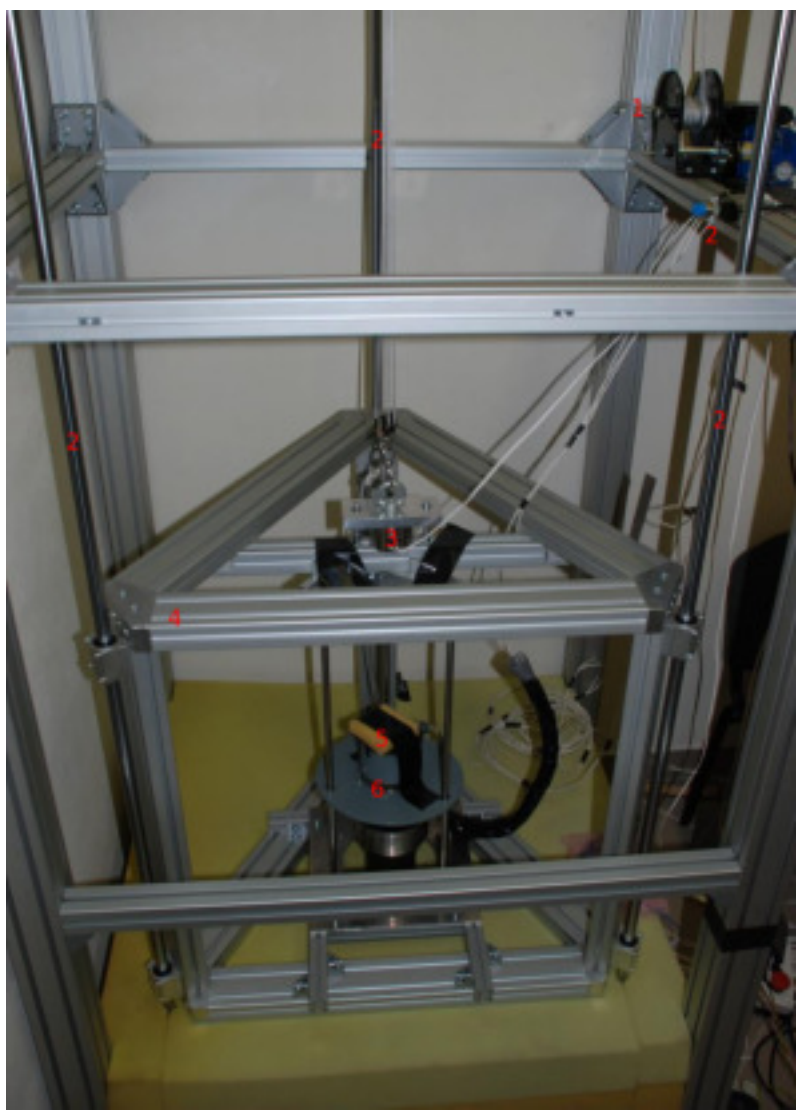

FiguRE 1. Drop tower setup (1 - motorized dropweight lift, 2 - trigger inductive sensor, 3 - guide rods, 4 - electromagnetic release member, 5 - drop-weight guide frame, 6 - accelerometer, 7 - drop-weight).

USA) with loading capacity $\pm 1000 g$ and impact force transducer (200C20, PCB Piezoelectronics, USA) with loading capacity $89 \mathrm{kN}$. Both accelerometer and force transducer were connected to read out electronics NI9234 (National Instruments, Inc., USA) providing sampling rate 51200 samples per second. For the observation of deformation process a high speed camera (IDT NX3, USA) was employed. The camera provided frame rate 2895 to $3310 \mathrm{fps}$ at resolution $768 \times 1312 \mathrm{px}$ and the exposure time varied from 89 to $115 \mu \mathrm{s}$. For illumination of the loading scene pair of flash illuminators Veritas Constellation 60 were used. The impact test setup is depicted in Figure 1 and Figure 2.

\subsection{IMPACT TEST PROCEDURE}

The impact tests were carried out in three arrangements with different initial height and mass of the impactor. In each arrangement a pair of samples from the group A (bulk gelatine) as well as from group B (polymer meshwork filled with gelatin) were tested. The initial heights and impactor masses are listed in Table 1 with corresponding impact energy, velocity and strain rate. The impact velocity was calculated using the initial heigt and gravity constant based on conservation of sum of kinetic and potential energy.

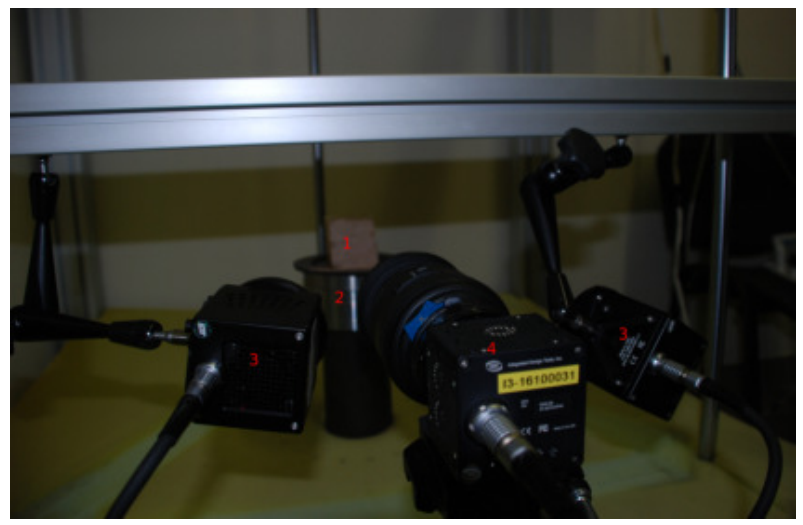

Figure 2. Drop tower setup (1 - specimen, 2 - impactor, 3 - flash-illumination, 4 - high-speed camera).

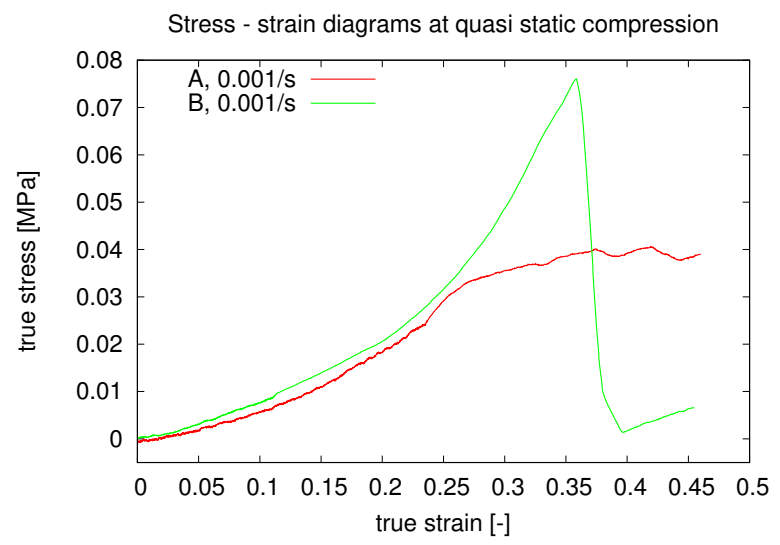

Figure 3. Stress-strain curves of quasi-static tests.

\section{Results}

From the quasi static loading test stress-strain curves which are depicted in Figure 3 were calculated based on the measured force $F$ and cross-head displacement $u$ by formulae

$$
\begin{gathered}
\sigma_{\text {eng }}=\frac{F}{A_{0}} \\
\text { and } \epsilon_{\text {eng }}=\frac{u}{l_{0}},
\end{gathered}
$$

where $A_{0}$ is specimen cross-section and $l_{0}$ is the initial gauge length.

The engingeering stress $\sigma_{\text {eng }}$ and strain $\epsilon_{\text {eng }}$ were then converted to logarithmic strain $\epsilon$ and true stress $\sigma$ using formulae

$$
\begin{gathered}
\epsilon=\ln \epsilon_{\mathrm{eng}} \\
\text { and } \sigma=\sigma_{\mathrm{eng}}\left(1+\epsilon_{\mathrm{eng}}\right) .
\end{gathered}
$$

To evaluate the drop tests stress-strain diagrams were created from the measured acceleration and force. While the stress is measured directly by force transducer, strain calculation is based on double time integration of the vertical component of acceleration. 


\begin{tabular}{lllll}
\hline arrangement & $\begin{array}{l}\text { initial height } \\
{[\mathrm{m}]}\end{array}$ & $\begin{array}{l}\text { drop weight } \\
{[\mathrm{kg}]}\end{array}$ & $\begin{array}{l}\text { impact velocity } \\
{\left[\mathrm{ms}^{-1}\right]}\end{array}$ & $\begin{array}{l}\text { impact energy } \\
{[\mathrm{J}]}\end{array}$ \\
\hline 1 & 1.00 & 4.495 & 4.4 & 44.1 \\
\hline 2 & 1.50 & 4.495 & 5.4 & 66.1 \\
\hline 3 & 1.50 & 6.504 & 5.4 & 95.7 \\
\hline
\end{tabular}

TABLE 1. Impact test parameters.

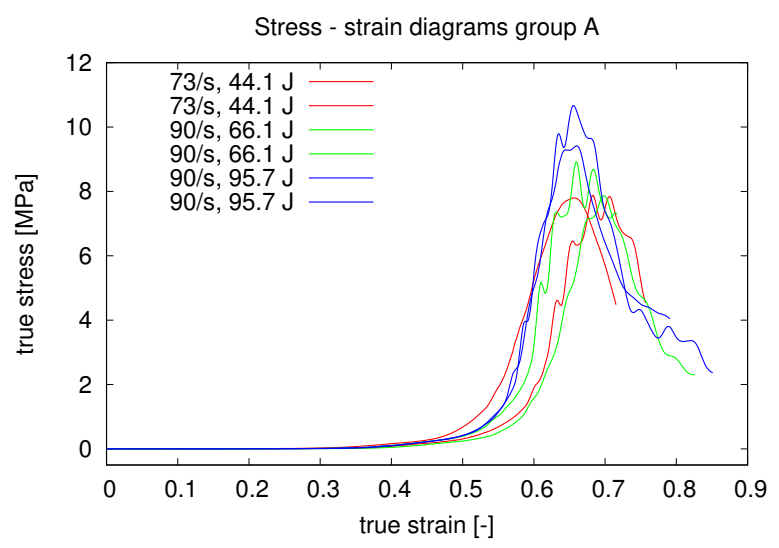

FiguRE 4. Stress-strain curves of drop tests of group A (ordnance gelatine).

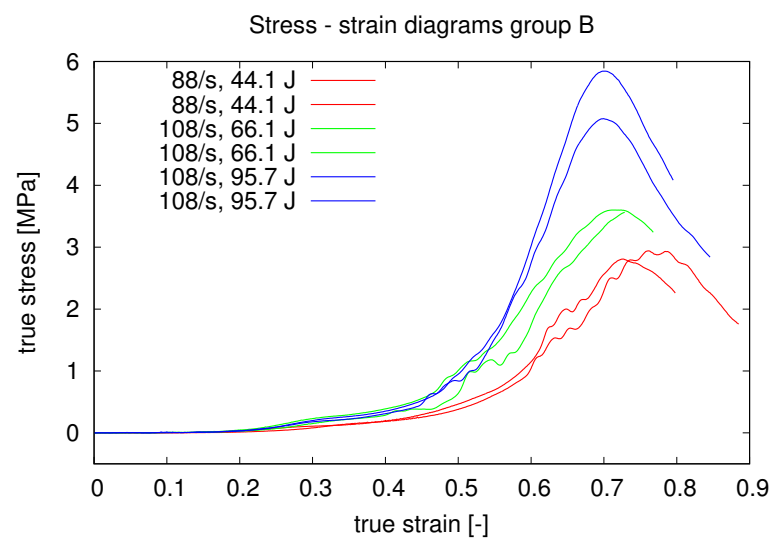

FiguRE 5. Stress-strain curves of drop tests of group B (polymer meshwork filled with ordnance gelatine).

Comparison of the stress-strain curves is depicted in Figure 5

For the assessment of dissipated impact energy strain energy density $\lambda$ was computed using formula

$$
\lambda=\int_{0}^{\epsilon_{\max }} \sigma \mathrm{d} \epsilon
$$

The obtained values are presented in Table 2 Moreover for visual evaluation of the deformation behaviour the captured loading scene was used (selected series of loading scenes in distinct loading steps is depicted in Figure 6).

\begin{tabular}{lll}
\hline $\begin{array}{l}\text { No. / } \\
\text { group }\end{array}$ & $\begin{array}{l}\text { strain energy } \\
\text { density }\left[\mathrm{Jcm}^{-3}\right]\end{array}$ & $\begin{array}{l}\text { peak } \\
\text { acceleration }\end{array}$ \\
\hline $1 / \mathrm{A} 1$ & 1.04503 & $234.92 \mathrm{~g}$ \\
\hline $2 / \mathrm{A} 1$ & 1.00956 & $209.23 \mathrm{~g}$ \\
\hline $3 / \mathrm{B} 1$ & 0.57674 & $95.01 \mathrm{~g}$ \\
\hline $4 / \mathrm{B} 1$ & 0.74435 & $94.07 \mathrm{~g}$ \\
\hline $5 / \mathrm{A} 2$ & 1.12309 & $210.53 \mathrm{~g}$ \\
\hline $6 / \mathrm{A} 2$ & 0.98409 & $231.10 \mathrm{~g}$ \\
\hline $7 / \mathrm{B} 2$ & 0.55441 & $149.72 \mathrm{~g}$ \\
\hline $8 / \mathrm{B} 2$ & 0.79479 & $147.84 \mathrm{~g}$ \\
\hline $9 / \mathrm{A} 3$ & 1.42620 & $199.30 \mathrm{~g}$ \\
\hline $10 / \mathrm{A} 3$ & 1.69909 & $223.24 \mathrm{~g}$ \\
\hline $11 / \mathrm{B} 3$ & 1.22701 & $152.42 \mathrm{~g}$ \\
\hline $12 / \mathrm{B} 3$ & 1.24369 & $148.73 \mathrm{~g}$ \\
\hline
\end{tabular}

TABLE 2. Impact test results.

\section{Conclusions}

An experimental study on deformation behaviour of ordnance gelatine and polymeric open-cell meshwork. From the results a significant strain-rate effect was observed in terms of ultimate compressive strength and strain energy density. In comparison of the deformation behaviour under quasi static conditions and drop weight test the difference was very significant, however slight increase in both strength and strain energy density was observed even between different impact energies and velocities during the impact testing.

The comparison between tested types of materials shows a significant reduction of the peak acceleration during the impact while the strain energy density decreased only slightly. This behaviour may be explained by the flow of the filling material thru the meshwork during the impact.

The obtained results will provide a base for further modelling of the impact energy dissipation as well as for optimisation of the filling material used in cellular solids.

\section{ACKNOWLEDGEMENTS}

The research was supported by the Czech Science Foundation (research project No. 15-15480S) and by 

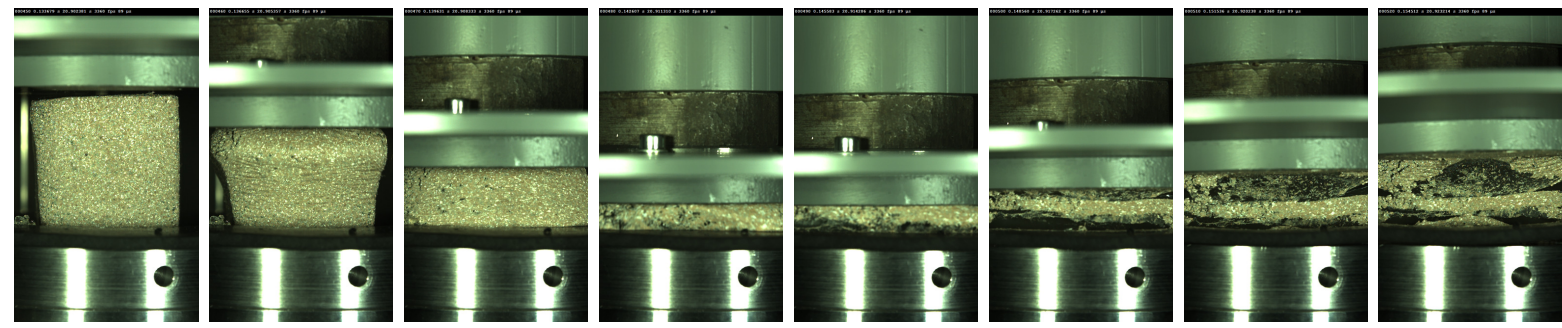

FiguRE 6. Loading scene of selected sample (group A3) in several loading steps (time step between captured images is $0.89 \mathrm{~ms}$ ).

Czech technical university in Prague (research projects SGS17/148/OHK2/2T/16 and SGS18/155/OHK2/2T/16). All the support is gratefully acknowledged.

\section{REFERENCES}

[1] P. Qiao, M. Yang, F. Bobaru. Impact mechanics and high-energy absorbing materials: Review. Journal of Aerospace Engineering 21(4):235-248, 2008. DOI:10.1061/(ASCE)0893-1321(2008)21:4(235)

[2] T. Doktor, P. Zlamal, T. Fila, et al. Properties of polymer-filled aluminium foams under moderate strain-rate loading conditions. Materiali in Tehnologije 49(4):597-600, 2015. DOI:10.17222/mit.2014.195.

[3] J. Breeze, M. Midwinter, D. Pope, et al. Developmental framework to validate future designs of ballistic neck protection. British Journal of Oral and Maxillofacial Surgery 51(1):47-51, 2013. DOI:10.1016/j.bjoms.2012.03.001
[4] J. Kwon, G. Subhash. Compressive strain rate sensitivity of ballistic gelatin. Journal of Biomechanics 43(3):420-425, 2010.

DOI:10.1016/j.jbiomech.2009.10.008

[5] J. Jussila. Preparing ballistic gelatine - review and proposal for a standard method. Forensic Science International 141(2-3):91-98, 2004. DOI:10.1016/j.forsciint.2003.11.036

[6] O. Jirousek, P. Zlamal, P. Koudelka, T. Fila. Development and validation of material models for closed-cell metal foam for impact simulation. Civil-Comp Proceedings 106, 2014. 